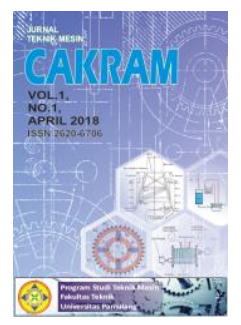

\title{
CAKRAM
}

\section{ANALISIS PERPINDAHAN PANAS PADA WATER JACKET DI RUANG BAKAR PRIMER INCINERATOR SAMPAH KOTA

\author{
Nailul 'Atifah ${ }^{1}$, Bambang Herlambang ${ }^{2}$, Edi Tri Astuti ${ }^{3}$, Yayan Mulyana ${ }^{4}$, \\ Perdamean Sebayang ${ }^{5}$
}

1,2,3,4,5 Program Studi Teknik Mesin, Universitas Pamulang, Jl. Surya Kencana No.1, Tangerang Selatan, Indonesia

E-mail : ${ }^{1}$ dosen00410@unpam.ac.id

Masuk: 13 Agustus $2020 \quad$ Direvisi : 4 September $2020 \quad$ Disetujui : 24 Septe2020

\begin{abstract}
Abstrak: Telah dilakukan penelitian mengenai analisis perpindahan panas pada water jacket di ruang bakar primer incinerator sampah kota. Analisis perpindahan panas dilakukan ketika water jacket berada dari fase cair hingga mencapai titik didihnya, yaitu $100{ }^{\circ} \mathrm{C}$, Suhu api pembakaran diasumsikan seragam berdasarkan hasil pengukuran api ruang bakar diperoleh nilai stabil yakni $1097{ }^{\circ} \mathrm{C}$. Variasi debit aliran water jacket adalah 300, 400, 500, dan 600 liter/jam. Tujuan penelitian ini adalah untuk mengetahui bagaimana kenaikan suhu dan karakteristik perpindahan panas pada water jacket dan pengaruh variasi debit terhadap kenaikan suhu water jacket di sepanjang ketinggian dinding ruang bakar. Penelitian dilakukan dengan melakukan perhitungan parameter termohidrolika yang merupakan fungsi suhu yang meliputi densitas, viskositas, konduktivitas, dan bilangan Prandtl. Kemudian, dilanjutkan dengan melakukan perhitungan bilangan Reynolds, Nusselt, koefisien perpindahan panas konveksi, Log Mean Temperature Difference (LMTD), resistensi termal total, dan laju perpindahan panas di sepanjang tinggi cerobong (L) sampai suhu air mencapai $100{ }^{\circ} \mathrm{C}$. Perhitungan tersebut dilakukan dengan metode Euler. Dari hasil perhitungan perpindahan panas diketahui bahwa suhu water jacket di sepanjang ketinggian dinding ruang bakar mengalami kenaikan hingga mencapai titik didihnya. Akan tetapi, ketika aliran water jacket semakin mencapai ke atas, gradien kenaikan suhunya mengalami penurunan nilai. Dengan demikian, laju perpindahan panasnya juga ikut mengalami penurunan. Dari variasi debit diperoleh hasil bahwa semakin besar debit aliran water jacket, kenaikan suhu yang dialami water jacket di sepanjang ketinggian ruang bakar juga semakin kecil. Dengan demikian semakin besar debit aliran water jacket, lintasan yang dibutuhkan untuk mencapai titik didihnya juga semakin panjang. Semakin besar debit aliran water jacket, maka laju perpindahan panas di posisi aliran yang sama juga semakin besar.
\end{abstract}

Kata kunci : perpindahan panas, water jacket, debit, suhu, incinerator.

\begin{abstract}
Research on heat transfer analysis on water jacket in primary combustion chamber of municipal solid waste incinerator has been conducted. Heat transfer analysis performed on the water jacket is carried out when the water jacket is from the liquid phase until it reaches its boiling point, which is $100^{\circ} \mathrm{C}$. The temperature of the combustion flame is assumed to be uniform, based on the measurement results of the combustion chamber flame, the stable value is $1097{ }^{\circ} \mathrm{C}$. The variations of the water jacket flow rate are 300, 400, 500, and 600 liters/hour. The purpose of this study was to determine how the temperature increase and heat transfer characteristics of the water jacket and the effect of the flow variation on the temperature increase of the water jacket along the height of the combustion chamber wall. The research was conducted by calculating the thermohydraulics parameters which are function of temperature. They are density, viscosity, conductivity, and Prandtl number. Then, it is proceed with calculating the Reynold number, Nusselt number, convection heat transfer coefficient, Log Mean Temperature Difference (LMTD), total thermal resistance, and heat transfer rate along the chimney height $(L)$ until the water temperature reaches $100^{\circ} \mathrm{C}$. The calculation is done using the Euler method. From the calculation of heat transfer it is known that the temperature of the water jacket along the height of the combustion chamber wall has increased until it reaches its boiling point. However, when the water jacket flow reaches upwards, the gradient of the increase in temperature decreases in value. Thus, the heat transfer rate also decreases. From the variation of the discharge, the result shows that the greater water jacket flow rate, the temperature increase experienced by the water jacket along the height of the combustion chamber is also getting smaller. Thus, the greater water jacket flow rate, the longer path needed to reach its boiling point. The greater water jacket flow rate, the heat transfer rate is greater at the same flow position.
\end{abstract}

Keywords : heat transfer, water jacket, flow rate, temperature, incinerator 


\section{PENDAHULUAN}

Salah satu alternatif untuk pengolahan sampah yang efektif adalah secara termal melalui pembakaran menggunakan incinerator. Kelebihan pengolahan sampah dengan incinerator adalah membutuhkan waktu yang lebih singkat untuk menguraikan sampah padat. Proses pembakaran mampu mengurangi volume sampah sampai 90\%[1]. Selain itu output yang dihasilkan sistem ini adalah berupa energi panas hasil pembakaran yang dapat dimanfaatkan sebagai sumber energi. Pengolahan sampah dengan insinerasi dapat mengurangi volume dan massa serta mengurangi sifat berbahaya dari sampah infeksius. Faktor yang memegang peranan penting dalam incinerator adalah temperatur pembakaran dan waktu pembakaran tersebut[2]. Pemanfaatan energi panas insinerasi identik dengan combustion yaitu dapat menghasilkan energi yang dapat dimanfaatkan. Faktor penting yang harus diperhatikan adalah kuantitas dan kontinuitas limbah yang akan dipasok. Kuantitas harus cukup untuk menghasilkan energi secara terbarukan agar penyuplaian energi tidak terputus[3].

Incinerator telah banyak digunakan diberbagai kota di Indonesia, akan tetapi incinerator yang digunakan masih belum optimal dan belum dapat menjawab semua permasalahan yang berhubungan dengan sampah dan lingkungan. Untuk menghadapi persoalan tersebut salah satu penelitian yang telah dilakukan adalah teknik pembakaran sampah terkontrol dengan alat incinerator dengan tujuan menurunkan volume sampah yang cukup besar[4]. Alat incinerator harus dilengkapi dengan sistem pengendalian dan kontrol untuk memenuhi batas-batas emisi partikel dan gas buang sehingga dipastikan asap yang keluar dari tempat pembakaran sampah merupakan asap/gas yang sudah netral[5].

Pada incinerator, isolator bagian furnace ada yang terbuat dari bata tahan api dan ada pula yang dilengkapi dengan water jacket. Pada penelitian ini, analisis perpindahan panas dilakukan pada incinerator yang menggunakan water jacket di bagian furnace-nya. Penambahan water jacket diharapkan dapat dijadikan isolator sekaligus untuk menghasilkan uap air. Dalam hal ini minimal diharapkan, listrik yang dihasilkan dari pembangkitan uap yang dialirkan pada turbin dapat digunakan untuk mensuplai energi listrik pada pengoperasian incinerator. Oleh karena itu, analisis perpindahan panas pada water jacket diperlukan untuk mengetahui pengaruh debit aliran air, terhadap kenaikan suhu dan perpindahan panasnya. Incinerator yang digunakan dalam penelitian ini memiliki kapasitas 50$70 \mathrm{~kg} / \mathrm{jam}$. Jenis sampah yang dibakar adalah sampah kota dari aktivitas domestik dan perkantoran.

\section{METODOLOGI}

Langkah-langkah penelitian dituliskan dalam bentuk narasi: (1), (2) Jumlah energi dari sebuah sistem tertutup akan tetap sama dan tidak berubah. Energi tersebut tidak dapat diciptakan maupun dimusnahkan namun dapat berubah dari satu bentuk energi ke bentuk energi lain[6,7]. Incinerator dapat merubah energi dalam bentuk sampah kota menjadi energi bentuk lain yaitu energi listrik. Analisis perpindahan panas pada water jacket melibatkan prinsip konduksi pada dinding ruang bakar (furnace) dan konveksi pada aliran airnya. Penampang skema water jacket yang akan dikaji pada penelitian ini ditunjukkan pada Gambar 1.

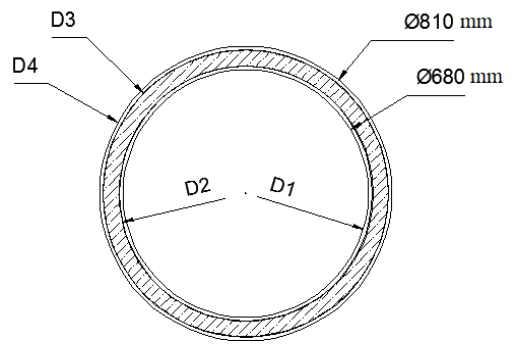

Gambar 1. Penampang Skema Water Jacket

Koefisien perpindahan panas konveksi pada water jacket dirumuskan dengan persamaan berikut[8]:

$$
h=\frac{N u \cdot k}{D_{h}}
$$


dengan:

h $\quad$ : koefisien perpindahan panas konveksi $\left(\mathrm{Watt} / \mathrm{m}^{2} \cdot{ }^{\circ} \mathrm{C}\right)$

$\mathrm{Nu} \quad$ : bilangan Nusselt

$\mathrm{k} \quad$ : konduktifitas air $\left(\mathrm{Watt} / \mathrm{m} .{ }^{\circ} \mathrm{C}\right)$

$\mathrm{D}_{\mathrm{h}} \quad$ : Diameter hidraulik (m)

Bilangan Nusselt merupakan bilangan yang tergantung pada bilangan Reynolds dan Prandtl[8]:

$$
N u=0,322 \cdot \operatorname{Re}^{0.5} \cdot \operatorname{Pr}^{(1 / 3)}
$$

dengan:

Pr : Bilangan Prandtl

Re : Bilangan Reynolds

Bilangan Reynolds dapat dihitung dengan persamaan[8]:

$$
\operatorname{Re}=\frac{\rho \cdot v \cdot D_{h}}{\mu}
$$

dengan:

$\rho \quad$ : massa jenis air $\left(\mathrm{kg} / \mathrm{m}^{3}\right)$

$\mathrm{v} \quad$ : kecepatan linier water jacket $(\mathrm{m} / \mathrm{s})$

$\mathrm{D}_{\mathrm{h}} \quad$ : diameter hidraulik (m)

$\mu \quad$ : viskositas air $(\mathrm{kg} / \mathrm{m} . \mathrm{s})$

Kecepatan linier water jacket yang mengalir dapat dirumuskan dengan persamaan berikut[8]:

$$
v=4 \frac{Q}{\pi\left(D_{3}{ }^{2}-D_{2}{ }^{2}\right)}
$$

dengan:

Q : debit water jacket $\left(\mathrm{m}^{3} / \mathrm{s}\right)$

$\mathrm{D}_{3} \quad$ : diameter bagian dalam dinding luar $(\mathrm{m})$

$\mathrm{D}_{2} \quad$ : diameter bagian luar dinding dalam $(\mathrm{m})$

Diameter hidraulik dapat dihitung dengan persamaan berikut[8]:

$$
D_{h}=\frac{4 . A_{h}}{P_{h}}
$$

dengan:

$\mathrm{A}_{\mathrm{h}} \quad$ : Luas penampang hidraulik $\left(\mathrm{m}^{2}\right)$

$\mathrm{P}_{\mathrm{h}} \quad$ : Perimeter hidraulik (m)

Perimeter hidraulik dirumuskan dengan persamaan berikut:

$$
P_{h}=\pi\left(D_{3}+D_{2}\right)
$$

Bilangan Prandtl dapat dihitung dengan persamaan berikut[6]:

$$
\operatorname{Pr}=\frac{c_{p} \cdot \mu}{k}
$$

dengan:

$\mathrm{c}_{\mathrm{p}} \quad$ : kalor jenis air pada tekanan tetap (Joule/kg. ${ }^{\circ} \mathrm{C}$ )

$\mu \quad$ : viskositas air $(\mathrm{kg} / \mathrm{m} . \mathrm{s})$

$\mathrm{k} \quad$ : konduktifitas air $\left(\mathrm{Watt} / \mathrm{m} .{ }^{\circ} \mathrm{C}\right)$ 
Skema perpindahan panas pada water jacket ditunjukkan pada Gambar 2.

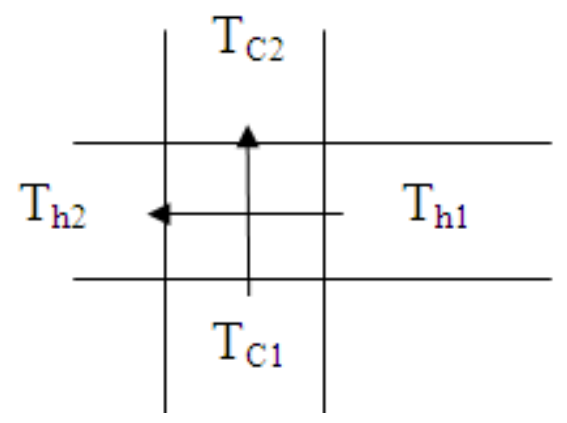

Gambar 2. Skema Perpindahan Panas pada Water jacket

Log Mean Temperature Difference (LMTD) pada perpindahan panas yang terjadi dapat dihitung dengan persamaan berikut[8]:

$$
L M T D=\frac{\left(T h_{2}-T c_{2}\right)-\left(T h_{1}-T c_{1}\right)}{\ln \left(\frac{T h_{2}-T c_{2}}{T h_{1}-T c_{1}}\right)}
$$

dengan:

$\mathrm{Th}_{2} \quad$ : suhu pada ruang bakar $\left({ }^{\circ} \mathrm{C}\right)$

$\mathrm{Th}_{1} \quad$ : suhu pada dinding luar $\left({ }^{\circ} \mathrm{C}\right)$

$\mathrm{Tc}_{2} \quad$ : suhu pada water jacket di bagian atas pada iterasi $\mathrm{z}_{\mathrm{i}+1}$ bakar $\left({ }^{\circ} \mathrm{C}\right)$

$\mathrm{Tc}_{1} \quad$ : suhu pada water jacket di bagian bawah pada iterasi $\mathrm{z}_{\mathrm{i}}\left({ }^{\circ} \mathrm{C}\right)$

Laju perpindahan panas dari dinding dalam bagian luar ruang bakar ke water jacket dapat dihitung dengan persamaan berikut[8]:

$$
Q=U . A . L M T D
$$

dengan:

Q : Laju perpindahan panas (Watt)

A : Luas perpindahan panas $\left(\mathrm{m}^{2}\right)$

LMTD : Log mean temperature difference $\left({ }^{\circ} \mathrm{C}\right)$

$\mathrm{U} \quad$ : koefisien perpindahan panas total $\left(\mathrm{Watt} / \mathrm{m}^{2} .{ }^{\circ} \mathrm{C}\right)$

Perpindahan panas dari dinding dalam ruang bakar ke dinding luar ditunjukkan pada Gambar 3.
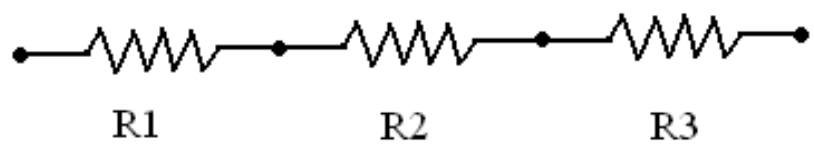

Gambar 3. Skema Perpindahan Panas dari Dinding Dalam ke Dinding Luar

R1, R2 dan R3 merupakan tahanan termal perpindahan panas secara berurutan adalah konduksi pada dinding dalam, konveksi pada water jacket, dan konduksi pada dinding luar.

Langkah-langkah yang dilakukan dalam penelitian ini meliputi:

1. Melakukan studi pustaka tentang incinerator dan spesifikasi incinerator CHUWASTAR.

2. Menyiapkan peralatan dan bahan yang digunakan untuk penelitian

3. Melakukan pengukuran suhu ruang bakar incinerator, suhu dinding luar dan dimensi

4. Melakukan perhitungan parameter termohidrolika yang merupakan fungsi suhu yang meliputi densitas air, viskositas air, konduktivitas air, dan bilangan Prandtl. 
5. Melakukan perhitungan bilangan Reynolds (Re), Nusselt (Nu), koefisien konveksi ( $\mathrm{h}_{\text {air }}$ ), Log Mean Temperature Difference (LMTD), panas sensibel (Q), resistensi termal total $\left(\mathrm{R}_{\mathrm{T}}\right)$, dan tinggi cerobong (L) sampai suhu air mencapai $100{ }^{\circ} \mathrm{C}$. Perhitungan dilakukan dengan metode Euler.

6. Langkah 4 dan 5 dilakukan pada variasi debit 300 1/jam, 400 1/jam, 500 1/jam dan 600 1/jam.

7. Melakukan analisis hubungan antara debit air, perubahan suhu air sepanjang tinggi cerobong dan ketinggian water jacket ketika suhu air mencapai $100^{\circ} \mathrm{C}$.

8. Membuat kesimpulan dari hasil analisis yang telah dilakukan.

Langkah-langkah kegiatan penelitian ditunjukkan pada Gambar 4.

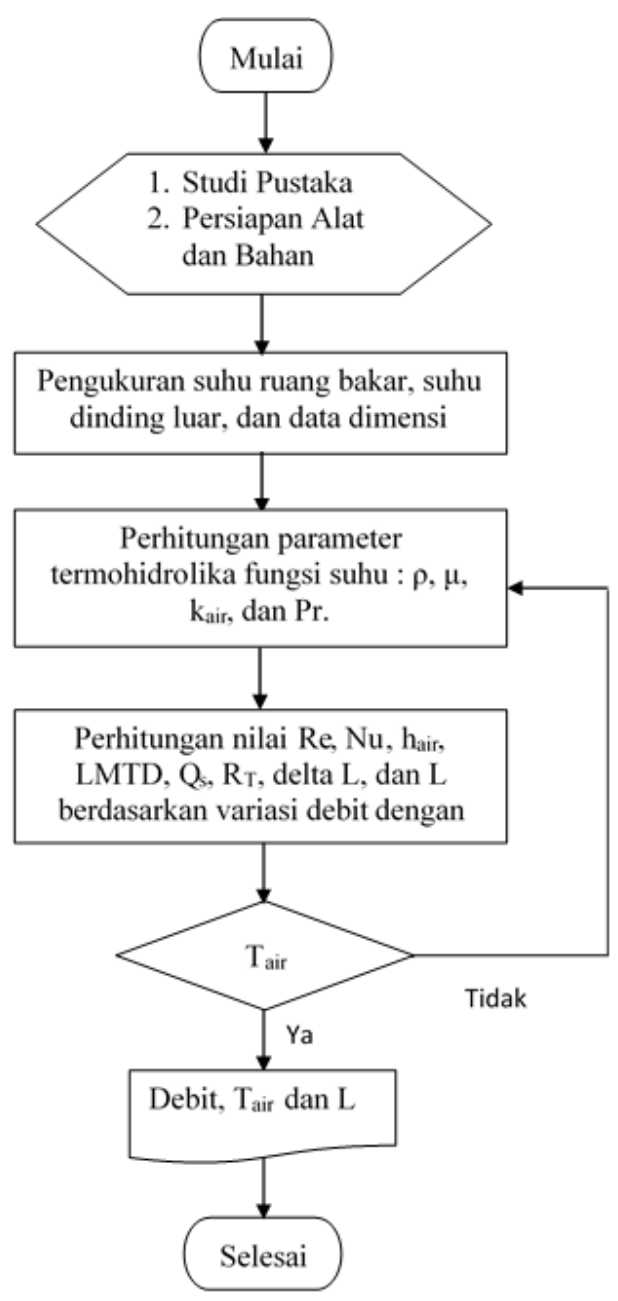

Gambar 4. Diagram Alir Penelitian

\section{HASIL DAN PEMBAHASAN}

Berikut ini contoh hasil perhitungan pada variasi debit 300 1/jam. Hasil perhitungan pada variasi debit yang lain bisa dilakukan pada program Ms. Excell. 
1. Menghitung keliling dalam

$$
\begin{aligned}
& K_{\text {in }}=\pi \cdot D_{\text {in }} \\
& K_{\text {in }}=3,14 \cdot 0,70 \mathrm{~m} \\
& K_{\text {in }}=2,19 \mathrm{~m}
\end{aligned}
$$

2. Menghitung keliling luar

$$
\begin{aligned}
& K_{\text {out }}=\pi \cdot D_{\text {out }} \\
& K_{\text {out }}=3,14 \cdot 0,79 \mathrm{~m} \\
& K_{\text {out }}=2,48 \mathrm{~m}
\end{aligned}
$$

3. Menghitung luas dalam water jacket yang dibasahi

$$
\begin{aligned}
& A_{\text {in }}=\frac{\pi \cdot D_{\text {in }}{ }^{2}}{4} \\
& A_{\text {in }}=\frac{3,14 \cdot(0,70 \mathrm{~m})^{2}}{4} \\
& A_{\text {in }}=0,38 \mathrm{~m}^{2}
\end{aligned}
$$

4. Menghitung luas luar water jacket yang dibasahi

$$
\begin{aligned}
& A_{\text {out }}=\frac{\pi \cdot D_{\text {out }}{ }^{2}}{4} \\
& A_{\text {out }}=\frac{3,14 \cdot 0,79^{2}}{4} \\
& A_{\text {out }}=0,49 \mathrm{~m}^{2}
\end{aligned}
$$

5. Menghitung perimeter hidraulik

$$
\begin{aligned}
& P h=K_{\text {out }}+K_{\text {in }} \\
& P h=2,48 m+2,19 m \\
& P h=4,67 m
\end{aligned}
$$

6. Menghitung luas penampang hidraulik

$$
\begin{aligned}
& A=\frac{\pi\left(D_{3}{ }^{2}-D_{2}{ }^{2}\right)}{4} \\
& A=\frac{3,14\left(0,79^{2}-0,70^{2}\right) m^{2}}{4} \\
& A=0,11 m^{2}
\end{aligned}
$$

7. Mengubah debit $300 \mathrm{l} / \mathrm{jam}$ menjadi satuan $\mathrm{m}^{3} / \mathrm{s}$

$$
\begin{aligned}
& Q=\frac{300}{3600000} \mathrm{~m}^{3} / \mathrm{s} \\
& Q=8,33.10^{-5} \mathrm{~m}^{3} / \mathrm{s}
\end{aligned}
$$


8. Menghitung kecepatan aliran

$$
\begin{aligned}
& v=\frac{Q}{A} \\
& v=\frac{8,33 \cdot 10^{-5} \mathrm{~m}^{3} / \mathrm{s}}{0,11 \mathrm{~m}^{2}} \\
& v=7,91 \cdot 10^{-4} \mathrm{~m} / \mathrm{s}
\end{aligned}
$$

9. Menghitung diameter hidraulik (D)

$$
\begin{aligned}
& D=\frac{4 \cdot A}{P h} \\
& D=\frac{4 \cdot 0,11 \mathrm{~m}^{2}}{4,67 \mathrm{~m}} \\
& D=0,09 \mathrm{~m}
\end{aligned}
$$

10. Menghitung Bilangan Reynolds

$$
\begin{aligned}
\operatorname{Re} & =\frac{\rho \cdot v \cdot D}{\mu} \\
\operatorname{Re} & =\frac{995,23^{\mathrm{kg}} / \mathrm{m}^{3} \cdot 7,91 \cdot 10^{-4} \mathrm{~m} / \mathrm{s} \cdot 0,09 \mathrm{~m}}{0,00068^{\mathrm{kg}} / \mathrm{m} \cdot \mathrm{s}} \\
\operatorname{Re} & =104,1
\end{aligned}
$$

11. Menghitung Bilangan Nusselt

$$
\begin{aligned}
& N u=0,332 \cdot \operatorname{Re}^{0,5} \cdot \operatorname{Pr}^{1 / 3} \\
& N u=0,332 \cdot 104,1^{0,5} \cdot 5,39^{1 / 3} \\
& N u=5,94
\end{aligned}
$$$$
h=\frac{N u \cdot K}{D} \quad h=\frac{5,94 \cdot 0.62 \mathrm{~W} / \mathrm{m} \cdot{ }^{\circ} \mathrm{C}}{0,09 \mathrm{~m}}
$$$$
h=40,92 \mathrm{~W} / \mathrm{m}^{2} \cdot{ }^{\circ} \mathrm{C}
$$ 
13. Menghitung Log Mean Temperature Difference (LMTD) pada $\Delta \mathrm{L}$ ke-1 Nilai 32,44 ${ }^{\circ} \mathrm{C}$ merupakan Tc2(i) kenaikan pertama

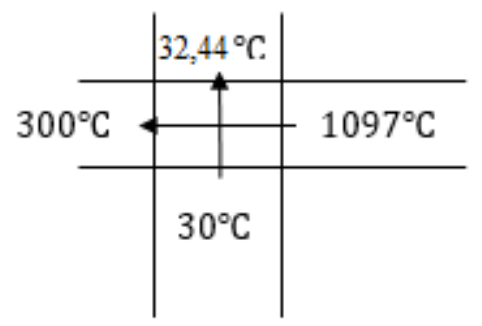

$$
\begin{aligned}
& L M T D=\frac{(T h 2-T c 2)-(T h 1-T c 1)}{\ln \frac{(T h 2-T c 2)}{(T h 1-T c 1)}} \\
& L M T D=\frac{(300-32,44)-(1097-30)}{\ln \frac{(300-32,44)}{(1097-30)}} \\
& L M T D=577,94{ }^{\circ} \mathrm{C}
\end{aligned}
$$

14. Menghitung Kalor Sensibel

$$
\begin{aligned}
& Q=\dot{m} \cdot c_{p} \cdot \Delta T \\
& Q=0,0829 \frac{\mathrm{kg}}{\mathrm{s}} \cdot 4,184 \frac{\mathrm{kJ}}{\mathrm{kg}}{ }^{\circ} \mathrm{C} \cdot 2,44{ }^{\circ} \mathrm{C} \\
& Q=0,8463 \mathrm{~kW}
\end{aligned}
$$

15. Menghitung Resistensi Termal

$$
\begin{aligned}
R h_{1} & =\frac{\ln \left(\frac{D_{2}}{D_{1}}\right)}{2 \cdot \pi \cdot k \cdot \Delta L} \\
R h_{1} & =\frac{\ln \left(\frac{0,70}{0,68}\right)}{2 \cdot 3,14 \cdot 45^{W} / m \cdot{ }^{\circ} \mathrm{C} \cdot 0,02 m} \\
R h_{1} & =0,00513^{\circ} \mathrm{C} / \text { Watt } \\
R h_{2} & =\frac{1}{\pi \cdot h \cdot D 2 \cdot \Delta L} \\
R h_{2} & =\frac{1}{3,14 \cdot 33,81 \text { W/ } /{ }^{2} \cdot{ }^{\circ} \mathrm{C} \cdot 0,68 m \cdot 0,02 m} \\
R h_{2} & =0,69261{ }^{\circ} \mathrm{C} / \text { Watt }
\end{aligned}
$$




$$
\begin{aligned}
R h_{3} & =\frac{\ln \left(\frac{D_{4}}{D_{3}}\right)}{2 \cdot \pi \cdot k \cdot \Delta L} \\
R h_{3} & =\frac{\ln \left(\frac{0,81}{0,79}\right)}{2 \cdot 3,14 \cdot 45^{W} / m \cdot{ }^{\circ} \mathrm{C}^{\cdot 0,02 \mathrm{~m}}} \\
R h_{3} & =0,00442^{\circ} \mathrm{C} / \text { Watt }
\end{aligned}
$$

16. Menghitung Hambatan termal

$$
\begin{aligned}
\text { Rtot } & =R h 1+R h 2+R h 3 \\
\text { Rtot } & =0,00513+0,69261+0,00442 \\
\text { Rtot } & =0,70216{ }^{\circ} \mathrm{C} / \text { Watt }
\end{aligned}
$$

\begin{tabular}{|c|c|c|c|c|}
\hline \multirow{2}{*}{$\begin{array}{l}\text { Panjang } \\
\text { (m) }\end{array}$} & \multicolumn{4}{|c|}{ Suhu Water Jacket $\left({ }^{\circ} \mathrm{C}\right)$} \\
\hline & $\begin{array}{c}\text { Debit } 300 \\
\text { (1/jam) }\end{array}$ & $\begin{array}{c}\text { Debit } 400 \\
\text { (1/jam) }\end{array}$ & $\begin{array}{c}\text { Debit } 500 \\
\text { (1/jam) }\end{array}$ & $\begin{array}{c}\text { Debit } 600 \\
(1 / \text { jam })\end{array}$ \\
\hline 0.00 & 30.00 & 30.00 & 30.00 & 30.00 \\
\hline 0.02 & 32.44 & 32.11 & 31.88 & 31.72 \\
\hline 0.04 & 34.98 & 34.29 & 33.83 & 33.48 \\
\hline 0.06 & 37.59 & 36.53 & 35.81 & 35.29 \\
\hline 0.08 & 40.26 & 38.82 & 37.84 & 37.13 \\
\hline 0.10 & 42.98 & 41.15 & 39.91 & 39.01 \\
\hline 0.12 & 45.75 & 43.52 & 42.01 & 40.91 \\
\hline 0.14 & 48.55 & 45.92 & 44.14 & 42.84 \\
\hline 0.16 & 51.39 & 48.35 & 46.30 & 44.79 \\
\hline 0.18 & 54.24 & 50.80 & 48.47 & 46.77 \\
\hline 0.20 & 57.09 & 53.27 & 50.66 & 48.75 \\
\hline 0.22 & 59.95 & 55.74 & 52.87 & 50.76 \\
\hline 0.24 & 62.80 & 58.21 & 55.08 & 52.77 \\
\hline 0.26 & 65.62 & 60.69 & 57.29 & 54.78 \\
\hline 0.28 & 68.42 & 63.15 & 59.50 & 56.80 \\
\hline 0.30 & 71.18 & 65.60 & 61.71 & 58.83 \\
\hline 0.32 & 73.89 & 68.02 & 63.91 & 60.84 \\
\hline 0.34 & 76.55 & 70.42 & 66.09 & 62.85 \\
\hline 0.36 & 79.14 & 72.78 & 68.26 & 64.85 \\
\hline 0.38 & 81.66 & 75.11 & 70.40 & 66.84 \\
\hline 0.40 & 84.09 & 77.39 & 72.52 & 68.81 \\
\hline 0.42 & 86.43 & 79.62 & 74.61 & 70.77 \\
\hline 0.44 & 88.67 & 81.79 & 76.66 & 72.70 \\
\hline 0.46 & 90.80 & 83.90 & 78.67 & 74.60 \\
\hline 0.48 & 92.80 & 85.94 & 80.64 & 76.47 \\
\hline 0.50 & 94.68 & 87.90 & 82.56 & 78.31 \\
\hline 0.52 & 96.41 & 89.78 & 84.42 & 80.12 \\
\hline 0.54 & 98.00 & 91.58 & 86.23 & 81.88 \\
\hline 0.56 & 99.43 & 93.28 & 87.98 & 83.61 \\
\hline
\end{tabular}
titik didih

Tabel 1 menunjukkan kenaikan suhu water jacket di sepanjang ketinggian ruang bakar sampai mencapai Tabel 1. Perubahan Suhu Water Jacket di Sepanjang Ketinggian Ruang Bakar 


\begin{tabular}{|c|c|c|c|c|}
\hline 0.58 & 100.69 & 94.88 & 89.67 & 85.29 \\
\hline 0.60 & & 96.38 & 91.28 & 86.92 \\
\hline 0.62 & & 97.77 & 92.82 & 88.49 \\
\hline 0.64 & & 99.04 & 94.29 & 90.01 \\
\hline 0.66 & & 100.18 & 95.67 & 91.48 \\
\hline 0.68 & & & 96.96 & 92.88 \\
\hline 0.70 & & & 98.16 & 94.21 \\
\hline 0.72 & & & 99.27 & 95.48 \\
\hline 0.74 & & & 100.28 & 96.68 \\
\hline 0.76 & & & & 97.80 \\
\hline 0.78 & & & & 98.84 \\
\hline 0.80 & & & & 99.80 \\
\hline 0.82 & & & & 100.68 \\
\hline
\end{tabular}

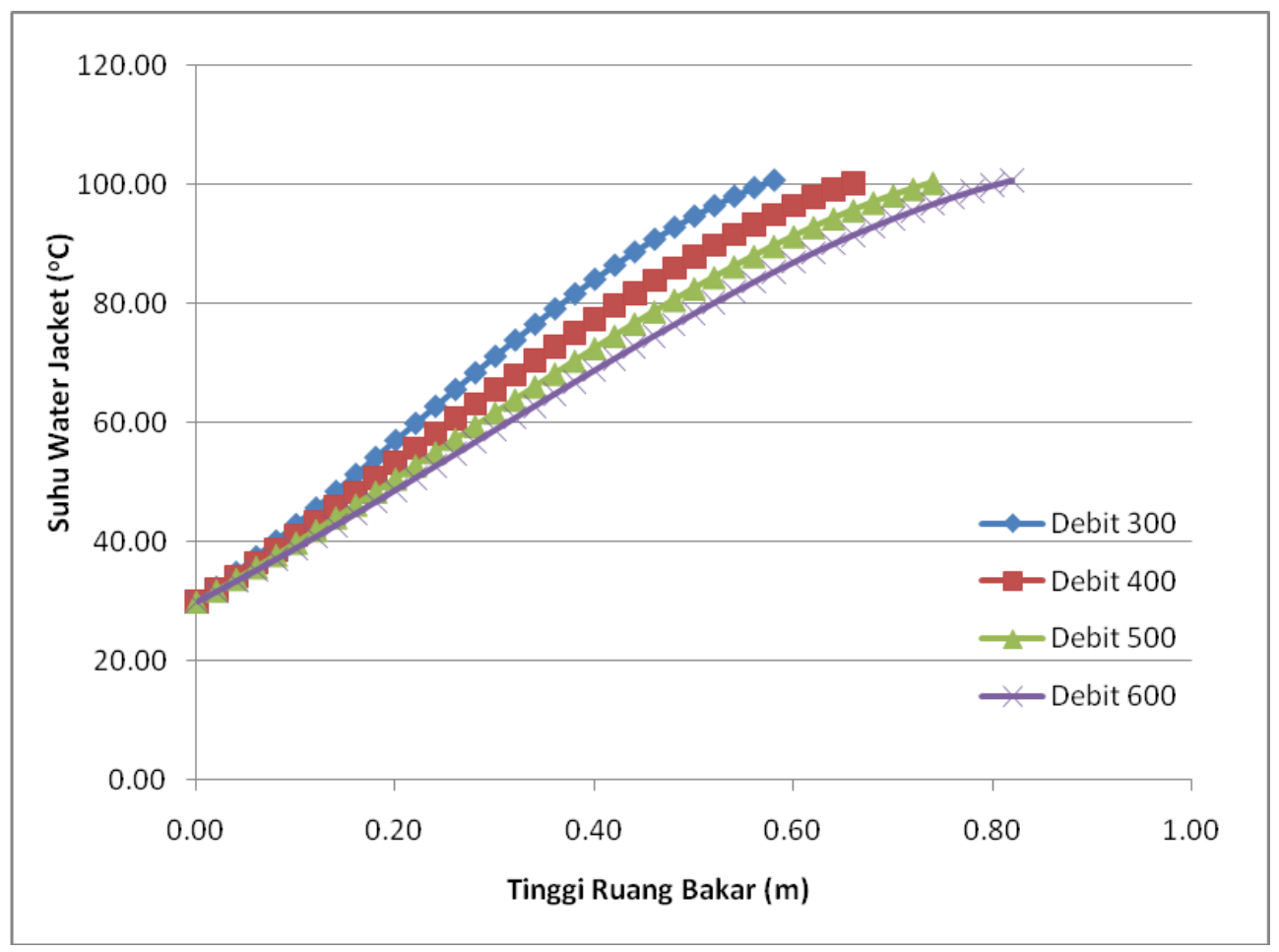

Gambar 5. Kenaikan Suhu Water Jacket di Sepanjang Ruang Bakar

Dari grafik diketahui bahwa gradien kemiringan suhu water jacket yang paling besar adalah pada debit aliran yang paling kecil yaitu 300 1/jam. Semakin kecil debit water jacket maka kenaikan suhu water jacket akan semakin besar. Hal ini terjadi karena debit yang kecil akan menyebabkan lama waktu kontak antara air dan dinding luar ruang bakar semakin lama.

Debit berpengaruh terhadap kenaikan suhu dan posisi water jacket mencapai titik didihnya. Pada debit yang divariasikan, debit 300 1/jam memberikan hasil kenaikan suhu per satuan panjang lintasan yang paling besar dibanding variasi debit yang lain. Semakin kecil debit, kenaikan suhu yang dialami water jacket per satuan panjang lintasan semakin besar sehingga water jacket semakin cepat mencapai titik didih, sebaliknya semakin besar debit, kenaikan suhu yang dialami water jacket per satuan panjang lintasan semakin kecil.

Dari hasil perhitungan perpindahan panas diketahui bahwa suhu water jacket di sepanjang ketinggian dinding ruang bakar mengalami kenaikan hingga mencapai titik didihnya. Pada debit 300 liter/jam, water jacket mencapai titik didih pada ketinggian 0,58 m. Pada debit 400 liter/jam, water jacket mencapai titik didih pada ketinggian 0,66 m. Pada debit 500 liter/jam, water jacket mencapai titik didih pada ketinggian 0,74 m. Pada debit 600 liter/jam, water jacket mencapai titik didih pada ketinggian 0,82 m. Ketika aliran water jacket semakin mencapai ke atas, 
gradien kenaikan suhunya mengalami penurunan nilai. Dengan demikian, laju perpindahan panasnya juga ikut mengalami penurunan.

Dari variasi debit diperoleh hasil bahwa semakin besar debit aliran water jacket, kenaikan suhu yang dialami water jacket di sepanjang ketinggian ruang bakar juga semakin kecil. Dengan demikian semakin besar debit aliran water jacket, lintasan yang dibutuhkan untuk mencapai titik didihnya juga semakin panjang.

Tabel 2. Laju Perpindahan Panas dari Ruang Bakar ke Water Jacket Sepanjang Ketinggian Ruang Bakar

\begin{tabular}{|c|c|c|c|c|}
\hline \multirow[b]{2}{*}{ Panjang (m) } & \multicolumn{4}{|c|}{ Laju Perpindahan Panas (kWatt) } \\
\hline & $\begin{array}{c}\text { Debit } 300 \\
\text { (l/jam) }\end{array}$ & $\begin{array}{c}\text { Debit } 400 \\
\text { (l/jam) }\end{array}$ & $\begin{array}{c}\text { Debit } 500 \\
\text { (1/jam) }\end{array}$ & $\begin{array}{c}\text { Debit } 600 \\
(1 / \text { jam })\end{array}$ \\
\hline 0.00 & 0.3469 & 0.4626 & 0.5782 & 0.6939 \\
\hline 0.02 & 0.3467 & 0.4624 & 0.5779 & 0.6936 \\
\hline 0.04 & 0.3464 & 0.4621 & 0.5776 & 0.6933 \\
\hline 0.06 & 0.3461 & 0.4618 & 0.5773 & 0.6929 \\
\hline 0.08 & 0.3458 & 0.4614 & 0.5769 & 0.6925 \\
\hline 0.10 & 0.3455 & 0.4610 & 0.5765 & 0.6921 \\
\hline 0.12 & 0.3451 & 0.4606 & 0.5760 & 0.6916 \\
\hline 0.14 & 0.3447 & 0.4601 & 0.5755 & 0.6911 \\
\hline 0.16 & 0.3442 & 0.4596 & 0.5750 & 0.6905 \\
\hline 0.18 & 0.3437 & 0.4591 & 0.5745 & 0.6899 \\
\hline 0.20 & 0.3433 & 0.4586 & 0.5739 & 0.6893 \\
\hline 0.22 & 0.3428 & 0.4580 & 0.5733 & 0.6887 \\
\hline 0.24 & 0.3422 & 0.4575 & 0.5727 & 0.6881 \\
\hline 0.26 & 0.3417 & 0.4569 & 0.5721 & 0.6874 \\
\hline 0.28 & 0.3412 & 0.4563 & 0.5714 & 0.6867 \\
\hline 0.30 & 0.3406 & 0.4557 & 0.5707 & 0.6860 \\
\hline 0.32 & 0.3401 & 0.4550 & 0.5701 & 0.6853 \\
\hline 0.34 & 0.3395 & 0.4544 & 0.5694 & 0.6846 \\
\hline 0.36 & 0.3390 & 0.4538 & 0.5687 & 0.6838 \\
\hline 0.38 & 0.3384 & 0.4531 & 0.5680 & 0.6831 \\
\hline 0.40 & 0.3379 & 0.4525 & 0.5673 & 0.6823 \\
\hline 0.42 & 0.3373 & 0.4519 & 0.5665 & 0.6815 \\
\hline 0.44 & 0.3368 & 0.4512 & 0.5658 & 0.6807 \\
\hline 0.46 & 0.3363 & 0.4506 & 0.5651 & 0.6800 \\
\hline 0.48 & 0.3358 & 0.4500 & 0.5644 & 0.6792 \\
\hline 0.50 & 0.3353 & 0.4494 & 0.5637 & 0.6784 \\
\hline 0.52 & 0.3349 & 0.4488 & 0.5630 & 0.6776 \\
\hline 0.54 & 0.3344 & 0.4482 & 0.5623 & 0.6768 \\
\hline 0.56 & 0.3340 & 0.4476 & 0.5616 & 0.6761 \\
\hline 0.58 & 0.3337 & 0.4471 & 0.5609 & 0.6753 \\
\hline 0.60 & & 0.4466 & 0.5603 & 0.6746 \\
\hline 0.62 & & 0.4461 & 0.5597 & 0.6738 \\
\hline 0.64 & & 0.4456 & 0.5590 & 0.6731 \\
\hline 0.66 & & 0.4451 & 0.5584 & 0.6724 \\
\hline 0.68 & & & 0.5579 & 0.6717 \\
\hline 0.70 & & & 0.5573 & 0.6710 \\
\hline 0.72 & & & 0.5568 & 0.6704 \\
\hline 0.74 & & & 0.5563 & 0.6697 \\
\hline 0.76 & & & & 0.6691 \\
\hline 0.78 & & & & 0.6686 \\
\hline 0.80 & & & & 0.6680 \\
\hline 0.82 & & & & 0.6675 \\
\hline
\end{tabular}




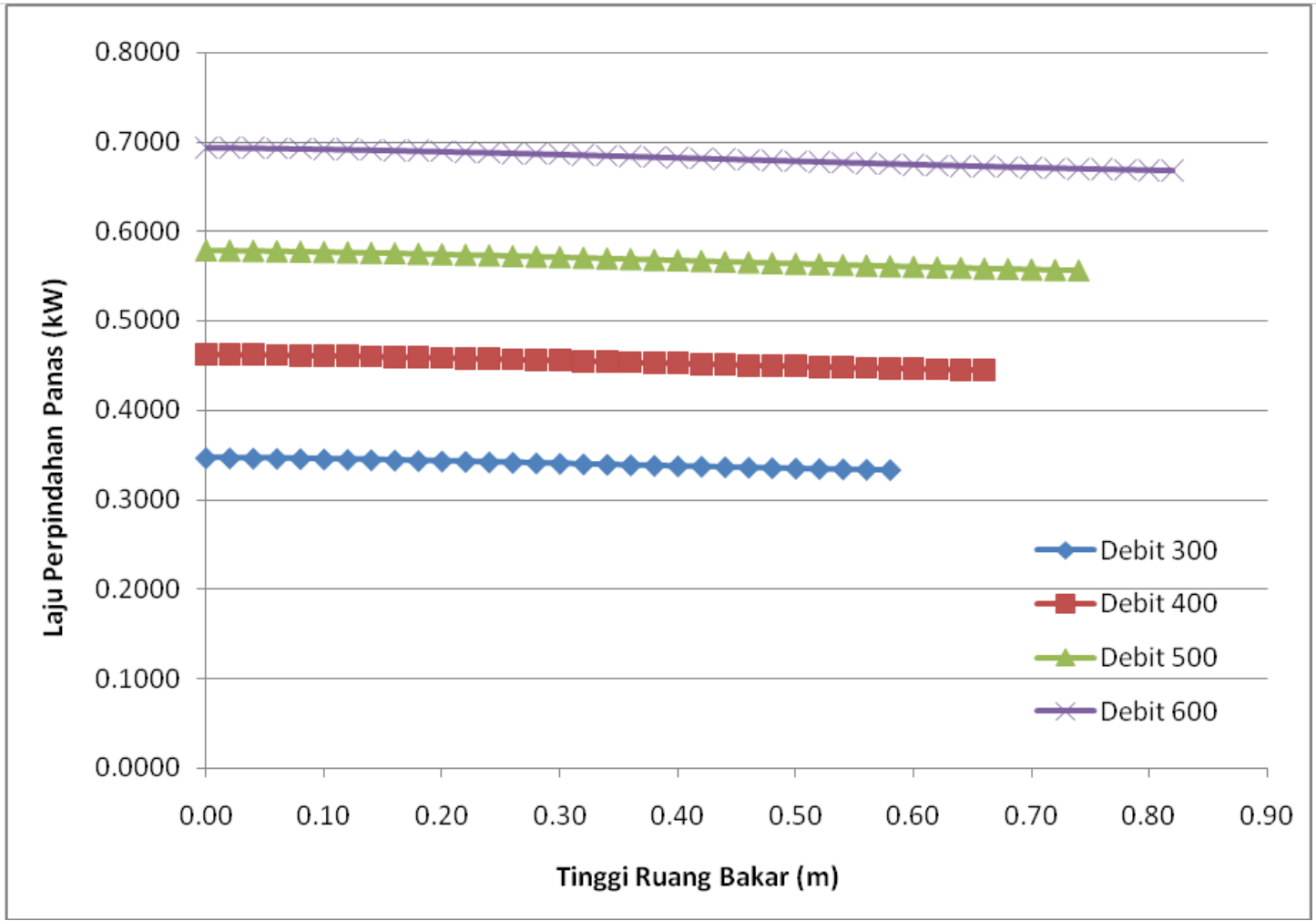

Gambar 6. Laju Perpindahan Panas dari Ruang Bakar ke Water jacket Sepanjang Ketinggian Ruang Bakar

Debit berpengaruh terhadap laju perpindahan panas dari dinding ruang bakar ke water jacket. Pada debit yang divariasikan, debit 600 l/jam memberikan laju perpindahan panas paling besar dibanding variasi debit yang lain. Semakin besar debit, laju perpindahan panas dari ruang bakar ke water jacket semakin besar, sebaliknya semakin kecil debit maka laju perpindahan panas juga semakin kecil. Hal ini terjadi karena laju perpindahan panas sebanding dengan laju aliran massa water jacket yang mengalir. Nilai debit yang akan dipilih tidak hanya dipengaruhi oleh laju perpindahan panas, tetapi juga tergantung pada parameter-parameter lain dan desain yang diharapkan.

\section{KESIMPULAN}

Kesimpulan dari penelitian ini adalah sebagai berikut:

1. Semakin kecil debit, kenaikan suhu yang dialami water jacket per satuan panjang lintasan semakin besar sehingga water jacket semakin cepat mencapai titik didih, sebaliknya semakin besar debit, kenaikan suhu yang dialami water jacket per satuan panjang lintasan semakin kecil. Pada debit 300 liter/jam, water jacket mencapai titik didih pada ketinggian $0,58 \mathrm{~m}$. Pada debit 400 liter/jam, water jacket mencapai titik didih pada ketinggian 0,66 m. Pada debit 500 liter/jam, water jacket mencapai titik didih pada ketinggian 0,74 m. Pada debit 600 liter/jam, water jacket mencapai titik didih pada ketinggian $0,82 \mathrm{~m}$.

2. Debit 600 1/jam memberikan laju perpindahan panas paling besar dibanding variasi debit yang lain. Semakin besar debit, laju perpindahan panas dari ruang bakar ke water jacket semakin besar, sebaliknya semakin kecil debit maka laju perpindahan panas juga semakin kecil. 


\section{DAFTAR PUSTAKA}

[1] Abdullah, dkk, 1998, Energi dan Listrik Pertanian, JICA, Bogor.

[2] Abbott, J.M. Smith, H.C. Van Ness, M.M. (2005). Introduction to chemical engineering thermodynamics. Boston ; Montreal: McGraw-Hill.

[3] Nilai Kalori Bahan Bakar, (http://yefrichan.wordpress.com/2013/12/02/ nilaikalori-bahan-bakar/)

[4] Budiman Arif. 2001. Modifikasi Desain dan Uji Unjuk Kerja Alat Pembakar Sampah (Incinerator) Tipe Batch. Skripsi. Jurusan Teknik Pertanian, Fakultas Teknologi Pertanian, IPB.

[5]Margarida J. Quina,dkk, 2011, Air Pullution Control in Municipal Solid Waste Incinerators, Intech(www.intechopen.com)

[6] Harahap, Gandhi, 1999, Perancangan Teknik Mesin, Penerbit: Erlangga, Jakarta .

[7] Holman, J.P., (Terjemahan: E. Jasjfi), 1984, Perpindahan Kalor, Penerbit: Erlangga, Jakarta.

[8] Geankoplis, Christie John (2003). Transport processes and separation process principles. Upper Saddle River, NJ: Prentice Hall Professional Technical Reference. ISBN 0- 13-101367-X. 